\title{
SELECTION OF REORDER POINT WHEN DEMAND IS VARIABLE AND ALSO LEAD TIME IS VARIABLE WITH DIFFERENT SIGNIFICANCE LEVEL TO DEMAND DEVIATION \& LEAD DEVIATION
}

\author{
Prof. Vinayak R. Bhavsar \\ M Tech, Balaji Institute of Modern Management Pune, India \\ Prof Dr. Binod Sinha \\ Balaji Institute of Modern Management Pune, India
}

\begin{abstract}
In material management Inventory control has significant importance, Inventory level decides reorder point, Due to deviations in demand \& lead time tendency is to keep safety to stock. In this paper various steps involved in calculating reorder points, have been given rethought by coming out with new formula based on different significance to demand deviation \& lead deviation This helps to improve reorder point and in turn lead time. Ultimately it helps to reduce safety stock due to different significance level for deviation in lead time and deviation in demand.
\end{abstract}

Keywords: Material management, Inventory carrying cost, reorder point, variable demand, variable lead time, Deviation in demand, deviation in lead time, different significance level for demand \& lead time deviation, calculating reorder point with different significance level.

Cite this Article: Prof. Vinayak R. Bhavsar and Dr. Binod Sinha, Selection of Reorder Point when Demand is Variable and also Lead Time is Variable with Different Significance Level to Demand Deviation \& Lead Deviation, International Journal of Management (IJM), 10 (6), 2019, pp. 235-238.

http://iaeme.com/Home/issue/IJM?Volume $=10 \&$ Issue $=6$

\section{INTRODUCTION}

In material management demand is variable all over the world, but lead time is fairly stable. But in some cases particularly in developing countries where supply chain logistics are not so strong \& also where electrical energy supply is available with interruptions lead to variations in lead time. In case of India lead time is also varying many time depending upon supply chain or electrical energy problems.

Reorder point in inventory system is normally at a point where Consumption in lead time is considered plus safety stock required a follows 
Reorder point $=$ average demand per unit time $*$ lead time + safety stock Here there are two factors involved, demand during lead time \& lead time both are variable but demand is rather more variable than lead time

\section{STEPS INVOLVED IN REORDER POINT}

Following steps are involved to arrive at reorder point

Service Level Policy: As the demand is assumed to be normally distribution with certain value of mean \& deviation $(\mu, \sigma)$. At mean $\mu$ only $50 \%$ service level is maintained hence there are $50 \%$ chances of exceeding the mean demand.Therefore 85 to $90 \%$ service level is normally considered by management. As per this \% criteria of service level, area of normal distribution to be covered for desired $\%$ is considered in to account, $Z_{d}$ value can be found out from normal distribution statistical table ( say for example for $90 \%$ area, $z_{d}$ value is +1.3 ) so the $Z_{d}$ value is worked out to be Consumption to be considered as $\mathrm{d}=\left(\mu_{d}+1.3 \sigma_{d}\right)$ for $90 \%$ service level with only $10 \%$ stock out risk.

Distributing this Demand over Lead Time: variation in demand plays important role in distribution of demand If we only consider variance in demand then total summation of variance in lead time would be

$$
\sigma_{d}^{2}+\sigma_{d}^{2}+\sigma_{d}^{2}+\ldots=\sigma_{d}^{2} L
$$

After getting total variance its standard deviation would be the square root of total variance

$$
\sigma_{d l . T}=\sqrt{\sigma_{d}^{2} L}=\sigma_{d} \sqrt{L}
$$

In the following example $\sigma_{\mathrm{d}}$ is taken as 15 and for 3 weeks it works out to be $15^{*} \sqrt{3}=25.98$ for $15^{*} \sqrt{L}$

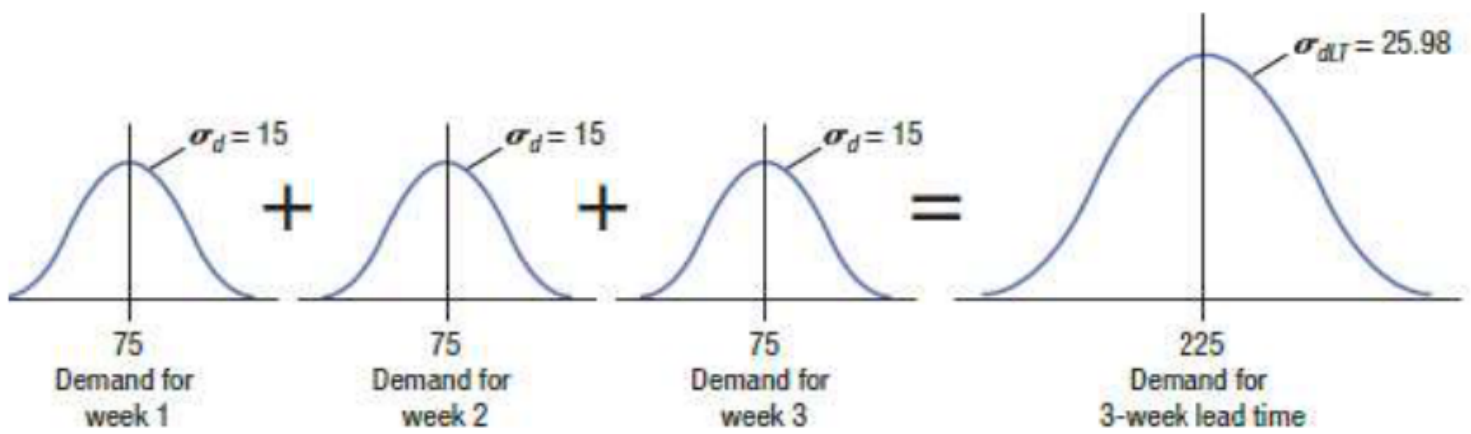

Next step is to find out safety stock \& finding out reorder point: Safety stock should be such that it should take care of variance in demand. There fore

$$
\text { Safety stock }=z_{d} \sigma_{\mathrm{d}}
$$

Where $\mathrm{z}_{\mathrm{d}}=$ Number of standard deviation needed to achieve service level

$\sigma_{\mathrm{d}}$ : standard deviation of demand during lead time

Then the new reorder point becomes

$$
R=d L+\text { safety stock }
$$

Where

$d$ :is average mean consumption rate per unit time $\left(\mu_{d}\right)$

$L:$ is average lead time $\left(\mu_{L}\right)$

$\sigma_{\mathrm{d}}$ : standard deviation of demand during lead time

$\sigma_{\mathrm{L}}$ : standard deviation of lead time 
For variation in demand consumption \& lead time there is prevailing formula as follow

$$
\left.d L+z_{d} \sqrt{\left(L \sigma_{d}^{2}\right.}+d^{2} \sigma_{L}^{2}\right)
$$

However with this formula $z_{d}$ is only taken into consideration and not $z_{L}$. Therefore it is required to have a formulation where we can have different and separate weightage to $z_{L} \&$ to $z_{d}$

\section{IMPROVEMENT SUGGESTED}

This has been worked out in different way where we can have separate importance to both variance of consumption $\&$ lead time. I am suggesting that

$$
R=d L+z_{d} \sigma_{\mathrm{d}} \sqrt{L}
$$

Let us consider that this $L$ lead time has $\left(\mu_{L}, \sigma_{L}\right)$ normal distribution then same formula can be transformed into

$$
R=d * L+z_{d} * \sigma_{\mathrm{d}} \sqrt{L+z_{L} \sigma_{L}}
$$

To correct it further, consumption during variation of lead time is required to be added.

Let $d * z_{L} * \sigma_{L}$ be the consumption during lead time deviation.

Reorder point $=$ Average consumption + deviation due to demand variation + Consumption during lead deviation

$$
\begin{aligned}
& R=d * L+z_{d} * \sigma_{\mathrm{d}} \sqrt{L+z_{L} \sigma_{L}}+d * z_{L} * \sigma_{L} \\
& R=d\left(L+z_{L} * \sigma_{L}\right)+z_{d} * \sigma_{\mathrm{d}} \sqrt{L+z_{L} \sigma_{L}} \\
& R=\mu_{d} * \mu_{L}+z_{d} * \sigma_{\mathrm{d}} \sqrt{\mu_{L}+z_{L} \sigma_{L}}+\mu_{d} * z_{L} * \sigma_{L} \\
& R=\mu_{d}\left(\mu_{L}+z_{L} * \sigma_{L}\right)+z_{d} * \sigma_{\mathrm{d}} \sqrt{\mu_{L}+z_{L} \sigma_{L}}
\end{aligned}
$$

Where

$R:$ is reorder level

$\mu_{L}:$ Mean lead time $=\mathrm{L}$

$\sigma_{L}:$ Standard deviation of lead time

$\sigma_{\mathrm{d}}$ : standard deviation of demand during lead time

$Z_{L ;}$ : Service level of lead time

$L:$ Average mean lead time

$d$; Average mean consumption per unit time $($ period $)=$

$z_{d}$ : Number of standard deviation needed to achieve desired service level

With the above formula we are in position to give different weightage to variance in demand $\&$ variance in lead time \&accordingly decide z value for each separately.

\section{CONCLUSION}

Thus it is now possible to offer different weightage according to the importance / significance to deviation of demand \& deviation of lead time . With these different significance values of demand deviation \& lead time deviation z values can be selected accordingly. Optimum reorder point can be achieved by giving appropriate significance two these entirely different parameter by selecting appropriate $\mathrm{zd}$ and $\mathrm{z}_{\mathrm{L}}$ values in formula. 
Selection of Reorder Point when Demand is Variable and also Lead Time is Variable with Different

Significance Level to Demand Deviation \& Lead Deviation

\section{REFERENCES}

[1] Greene, James H Production \& Inventory control handbook $3^{\text {rd }}$ edition New York Mc Graw Hill 1997

[2] Afolabi, Adedeji, Ojelabi, Rapheal, Tunji-Olayeni, Patience, Omuh, Ignatius and Adedotun Akinola, Data Architecture of Building Materials Using WebBased Technologies For Sustainable Material Management, International Journal of Mechanical Engineering and Technology, 9(6), 2018, pp. 1141-1154.

[3] Inventory Management Reprint Falls Church, VA, American Production and Inventory control society Management, 1993

[4] AparnaShruthi E and Dr.C.Venkatasubramanian Factors Affecting Material Management in Construction Industry, International Journal of Civil Engineering and Technology, 8(5), 2017, pp. 869-880.

[5] Tersine Richard J. Principles of Inventory Material Management $4^{\text {th }}$ Edition Upper saddle river. NJ Prentice Hall 1994.

[6] Kathika.K And Vidya.D.Avadhani, Material Management Practices Followed in Manufacturing Industry: Evidence from Selected Companies in Mysore City, international Journal of Civil Engineering and Technology, 9(11), 2018, pp. 1927-1931.

[7] Vendor-Managed Inventory In The Retail Supply by Matt Waller University of Arkansas M. Eric Johnson Vanderbilt University And Tom Davis Hewitt-Packard Company

[8] Dr. Rampilla Mahesh, Prominence of Material management in casting industry, International Journal of Mechanical Engineering and Technology, 9(5), 2018, pp. 1-6.

[9] Allioni, Gianpaolo, Xavier de Montgros, Regine Slagmulder, Luk N Van et al: Inventory driven cost, Harvard business Review Mar 2005 